\title{
The impact of the enrichment of the radionuclide thorium in the water body caused by industrial mining on the local ecological environment
}

\author{
Fengjiao $\mathrm{Hu}^{1}$, Li Deng ${ }^{2}$ and Zhichao Chen ${ }^{3}$ \\ ${ }^{1}$ Zhangye Radiation Environmental Management Station, Zhangye 734000,China \\ ${ }^{2}$ Zhangye Ecological Environment Monitoring Center of Gansu Province, Zhangye 734000,China \\ ${ }^{3}$ NARI Group Corporation(State Grid Electric Power Research Institute), Nanjing 21110,China
}

\begin{abstract}
In order to further understand the impact of industrial mining on the environment, this study conducted environmental monitoring on the radionuclide thorium content in a water body in an industrial mining area in Gansu Province, aiming to fully understand the occurrence of radioactive map elements in the area and its impact on the local. The specific impact caused by the ecological environment. The results of this paper are as follows: In the water environment surveyed this time, surface water has the highest content of radioactive thorium at $0.2 \mu \mathrm{g} / \mathrm{L}$, and the lowest concentration of radioactive thorium in groundwater, with an average concentration of $0.04 \mu \mathrm{g} / \mathrm{L}$. And with the depth of surface water sampling, there is a negative correlation between the content of thorium in the water. This research content can provide sufficient reference materials for the occurrence of thorium in the water in industrial mining areas, and is of great significance to the related research on radioactive elements in the water.
\end{abstract}

\section{Introduction}

At this stage, the shortage of human resources has seriously affected the further development of society. For this reason, the country has actively launched the mining of my country's mineral resources in order to further expand energy reserves and improve my country's comprehensive competitiveness[1]. The scale of industrial mining in my country is expanding. Take Gansu Province as an example. There are nearly 4,000 mining areas in Gansu Province, among which there are 134 large-scale mining areas[2]. The development of industrial mining not only greatly promoted local construction, but also brought huge economic benefits. However, the environmental problems caused by industrial mining are also worthy of our attention. Studies have shown that industrial mining will have a huge impact on water bodies, soil and air, and pose a serious threat to human life and health[3]. In the process of mineral development, the mining of rare earth ore resources has gradually received extensive attention from researchers. In the process of mining, the accompanying element of rare earth elements, namely thorium, has gradually attracted attention. Studies have shown that rare earth elements and thorium elements will enter the water body during the mining process, and then

\footnotetext{
a Corresponding author: tyek5@idhfund.com
}

enter the ecosystem through material circulation, posing a serious threat to the natural ecosystem environment[4].

With the advancement of technology and the improvement of people's ecological awareness, environmental monitoring has gradually attracted the attention of the whole society. Environmental monitoring is of great significance in environmental protection in our country, especially in the research and analysis of environmental pollution problems caused by industrial mining. Environmental monitoring can systematically and comprehensively monitor the environment around the area. There is also a comprehensive understanding of thequality[5].Inmonitoring,environmental monitoring is a monitoring method that can evaluate the radioactive substances released into the environment by surrounding facilities, monitor and evaluate its long-term trends, and find problems and improve them in time[6]. Especially in the context of the rapid development of my country's nuclear energy industry, it is of great significance. Many researchers have series of environmental monitoring work on radioactive elements such as thorium in the environment and obtained sufficient and reliable environmental data. Zhu Lietal[7].studied thorium and other radioactive elements in a uranium mine, and the results showed that rainfall factors can directly affect the release of thorium. Zhang Bin[8] showed that although 
uranium waste rock piled in the open air along the valley will have certain impact on the environment, the thorium element in it has little impact on the surrounding environment.

Based on the actual situation during environmental monitoring, this study took an industrial mining area in Gansu Province as the research area, and investigated the radionuclide thorium content in the surface water, drinking water and groundwater environment of the industrial mining area by spectrophotometry. Based on the corresponding analysis results, the environmental and ecological pollution caused by the radionuclide thorium was evaluated.

\section{Method}

\subsection{The properties of the radionuclide thorium}

Thorium is a kind of radioactive metal element with active chemical properties. It is a potential nuclear fuel, and it has very considerable application prospects in the research and development of energy materials in the future. The production of thorium is abundant in my country, but in the past, due to technical limitations and research limitations, thorium ore has been ignored by the public. With the development of technology and the deepening of research, the role of thorium is gradually being noticed and valued by the public. In recent years, nuclear energy system projects centered on thorium have been launched one after another. Thorium is widely used in molten salt heat storage, high-temperature hydrogen production, etc., and is closely integrated with wind power, photovoltaic industry, and coal chemical industry to achieve green industry development from the supply side.

As a radioactive element, the harm of thorium to the human body is also not small. Thorium is a natural radioactive substance, which can emit three kinds of rays: $\alpha, \beta$, and $\gamma$. Long-term exposure can cause genetic mutations in humans and endanger health. Studies have shown that dogs inhaled $76 \mathrm{mg}$ of thorium nitrate and $\mathrm{m} 3$ for a short period of time and have symptoms of vomiting and coughing.

\subsection{Water sampling method}

The sampling points for this study mainly selected surface water, drinking water and groundwater in the industrial mining area, and samples were taken in May. The surface water is taken from the river near the industrial zone. Drinking water is taken from nearby residents' tap water pipes and water in reservoirs, while groundwater is taken from villagers drinking groundwater. The specific sampling points are shown in the following table:

Table 1. Overview of sampling point distribution.

\begin{tabular}{|c|c|c|c|}
\hline sampling type & sampling location & $\begin{array}{c}\text { number of sampling } \\
\text { points }\end{array}$ & sampling time \\
\hline
\end{tabular}

\begin{tabular}{|c|c|c|c|}
\hline surface water & river & 6 & 5 \\
\hline drinking water & $\begin{array}{c}\text { reservoir water, pipe } \\
\text { water }\end{array}$ & 12 & 5 \\
\hline groundwater & groundwater well & 10 & 5 \\
\hline
\end{tabular}

The sampling method of this study strictly follows the relevant national regulations. All sampling personnel must undergo relevant training before sampling, and a sampling plan and sampling route must be fully developed before sampling. Sampling equipment and transportation communication tools, and the safety of sampling equipment and personnel should be ensured during sampling. When sampling, the water harvester is made of plexiglass, and the water storage device is a plastic bucket made of polyethylene.

The following points should be paid attention to when collecting surface water: (1) The sampling should be carried out from top to bottom when the stratified sampling method is adopted to avoid mixing of different levels of water bodies and affecting the sampling effect. (2) When sampling, the sampler should be rinsed 3 times with the sampling water, and then the sampling work should be carried out. Pay attention to the following points when sampling groundwater and drinking water.:(1) When taking water from water pipes and wells, the water pipes and wells commonly used by residents should be selected. (2) When using water pipes for sampling, water should be discharged first, so that the residual water in the water pipe can flow out before sampling. (3) When using a pump to pump water, the amount of water released in time can be sampled after 3 times the sampling volume.

\subsection{The detection and analysis method of thorium element}

The detection method of thorium element selected in this study is the analysis and detection method of surface water, groundwater and the thorium element in the cited water specified by the national standard, mainly using spectrophotometry for detection. The detection steps are as follows: Firstly, the water sample is added to the magnesium carrier and sodium hydroxide to form a coprecipitation of thorium and magnesium hydroxide products. Secondly, concentrated nitric acid is used to dissolve the co-precipitate, and the dissolved solution is passed through the trialkylphosphine oxide extraction resin to extract the chromatography layer on the selective adsorption column. Then use oxalic acid-hydrochloric acid solution to dissolve thorium. In the oxalic acidhydrochloric acid medium, thorium will form a red complex with azodipine III, and then the absorbance is measured at $660 \mathrm{~nm}$ in a spectrophotometer.

\section{Results and discussion}

\subsection{Existing status of radionuclide thorium in} the water in the study area 
(1) Existing status of the radionuclide thorium in surface water

There are a total of 6 main sampling points in the surface water sampling points, and the stratified sampling is carried out every $15 \mathrm{~cm}$ within the 6 sampling points. The main sampling points are river water systems. The main sampling results are shown in the figure below: As can be seen from the figure, sampling from No. 1 to No. 6 The concentrations of the radionuclide thorium in the surface water samples of the rivers in the point were $0.16 \mu \mathrm{g} / \mathrm{L}, 0.27 \mu \mathrm{g} / \mathrm{L}, 0.19 \mu \mathrm{g} / \mathrm{L}$, $0.21 \mu \mathrm{g} / \mathrm{L}, 0.20 \mu \mathrm{g} / \mathrm{L}$ and $0.17 \mu \mathrm{g} / \mathrm{L}$, respectively. Among them, the highest content of thorium is the sampling point No. 2 with a concentration of $0.27 \mu \mathrm{g} / \mathrm{L}$, and the lowest content is the sampling point No. 1 with a concentration of $0.16 \mu \mathrm{g} / \mathrm{L}$. The results of stratified sampling show that as the sampling depth gradually deepens, the content of the radionuclide thorium in the water body also decreases, and the content of the radionuclide thorium has a negative correlation with the sampling depth.

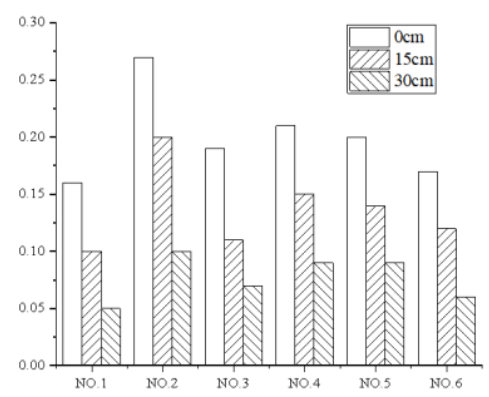

Figure 1 The concentration of thorium in the surface water of the study area.

(2) Existing status of radionuclide thorium in drinking water

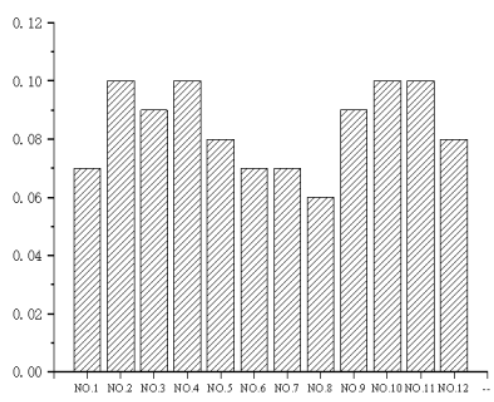

Figure 2 The concentration of thorium in the surface water of the study area.

In this study, the concentration of the radionuclide thorium in drinking water was also detected. The results are shown in Figure 2: As can be seen from the figure, a total of 12 sampling points are labeled $1-12$, and the concentration of thorium at the sampling points is $0.07 \mu$ $\mathrm{g} / \mathrm{L}, 0.10 \mu \mathrm{g} / \mathrm{L}, 0.09 \mu \mathrm{g} / \mathrm{L}, 0.10 \mu \mathrm{g} / \mathrm{L}, 0.08 \mu \mathrm{g} / \mathrm{L}, 0.07$ $\mu \mathrm{g} / \mathrm{L}, 0.07 \mu \mathrm{g} / \mathrm{L}, 0.06 \mu \mathrm{g} / \mathrm{L}, 0.09 \mu \mathrm{g} / \mathrm{L}, 0.10 \mu \mathrm{g} / \mathrm{L}$, $0.10 \mu \mathrm{g} / \mathrm{L}$ and $0.08 \mu \mathrm{g} / \mathrm{L}$. The highest concentration is
$0.10 \mu \mathrm{g} / \mathrm{L}$ and the lowest concentration is $0.06 \mu \mathrm{g} / \mathrm{L}$. The average concentration is $0.08 \mu \mathrm{g} / \mathrm{L}$.

(3) Existing status thorium radionuclide in groundwater

The content of thorium in groundwater is shown in Figure 3: It is known that there are 10 sampling points in total in groundwater samples, and the content of thorium is in order: $0.05 \mu \mathrm{g} / \mathrm{L}, 0.04 \mu \mathrm{g} / \mathrm{L}, 0.05 \mu \mathrm{g} / \mathrm{L}, 0.03 \mu \mathrm{g} / \mathrm{L}$, $0.04 \mu \mathrm{g} / \mathrm{L}, 0.04 \mu \mathrm{g} / \mathrm{L}, 0.04 \mu \mathrm{g} / \mathrm{L}, 0.05 \mu \mathrm{g} / \mathrm{L}, 0.03 \mu \mathrm{g} / \mathrm{L}$ and $0.06 \mu \mathrm{g} / \mathrm{L}$. The highest concentration appeared at point 10 , the radionuclide concentration was $0.06 \mu \mathrm{g} / \mathrm{L}$, the lowest concentration was at point 9 , and the radionuclide concentration was $0.03 \mu \mathrm{g} / \mathrm{L}$.

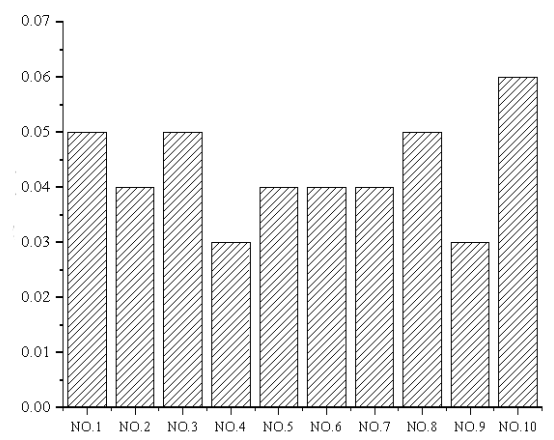

Figure 3 The concentration of thorium in groundwater in the study area.

\subsection{Overall Evaluation of Thorium Ecological Environment in Thorium Element Research Area}

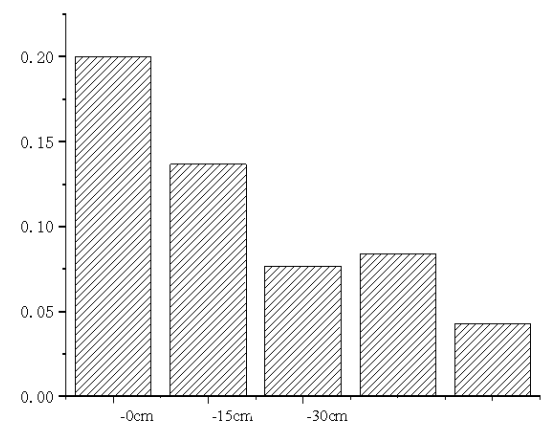

Figure 4 The overall distribution of thorium in the water environment in the study area.

Through data analysis and analysis of the data of thorium in the water samples detected, the overall distribution of the radionuclide thorium in the water body of the study area is obtained. The specific results are shown in Figure 4: It is known that in the overall water environment of the study area, the surface Water has the highest concentration of thorium with an average concentration of $0.2 \mu \mathrm{g} / \mathrm{L}$, and groundwater has the lowest concentration of thorium with an average concentration of $0.04 \mu \mathrm{g} / \mathrm{L}$. The average concentration 
of drinking water is $0.08 \mu \mathrm{g} / \mathrm{L}$. The average concentrations of $0 \mathrm{~cm}, 15 \mathrm{~cm}$ and $30 \mathrm{~cm}$ in surface water are $0.2 \mu \mathrm{g} / \mathrm{L}, 0.13 \mu \mathrm{g} / \mathrm{L}$ and $0.07 \mu \mathrm{g} / \mathrm{L}$, respectively. The content of thorium decreases with the increase of the depth of surface water.

At the same time, the study analyzed the standard deviation of the content of thorium in the measured water body. The results showed that the surface water$0 \mathrm{~cm}$ group has the largest standard deviation, which is related to the susceptibility of surface water to the surrounding environment. The minimum standard deviation is the groundwater group. This is because the impact of environmental pollution factors on groundwater is delayed and the pollution rate is slow.

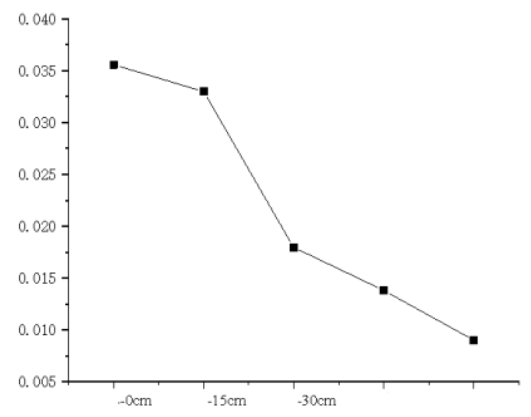

Figure 5 The standard deviation of the content of thorium in the water in the study area

Based on the research data, the investigation and analysis of thorium in the vicinity of the industrial mining area shows that the overall range of thorium in the water body in the study area remains within the range of $0.03 \mu \mathrm{g} / \mathrm{L}-0.27 \mu \mathrm{g} / \mathrm{L}$. The total average concentration in the water environment is $0.098 \mu \mathrm{g} / \mathrm{L}$. Among them, the value of point 2 in the surface water detection is the largest, and the environment near this point needs to be monitored in future research. A comprehensive comparison of the published relevant data shows that the residual level of thorium in the water in this industrial mining area is treated to the middle level in my country. Compared with other non-industrialized areas, the data is relatively large, but it is obvious that a rare earth mine in Jieyang City, Guangdong Province is relatively Concentrated area.

\section{In conclusion}

This study investigated and studied the value of thorium in different water environments around an industrial mining area in Gansu Province, aiming to further understand the specific situation of radioactive thorium in the water in the area. A total of 18 surface water samples were collected for drinking. 12 water samples and 10 groundwater samples. The relevant conclusions of the study are as follows: the surface water in the study area has the highest content of thorium, with an average concentration of $0.2 \mu \mathrm{g} / \mathrm{L}$, and the lowest concentration of groundwater with an average concentration of $0.04 \mu$ $\mathrm{g} / \mathrm{L}$, and the average concentration of the average radionuclide thorium in drinking water. It is $0.08 \mu \mathrm{g} / \mathrm{L}$. The overall range of thorium in the water in the study area is between $0.03 \mu \mathrm{g} / \mathrm{L}$ and $0.27 \mu \mathrm{g} / \mathrm{L}$, and the total average concentration in the water environment in the industrial zone is $0.098 \mu \mathrm{g} / \mathrm{L}$. At the same time, as the depth of surface water sampling gradually increased, the content of thorium in the surface water gradually decreased. The content of this study is of great significance for understanding the content of radioactive elements in the water in the study area. It is worth noting that the sampling time of this study is the high water period of the middle river in May. The subsequent experiments will further study the changes of thorium in the water body during the dry season, and further enrich the research content, in order to seek this industrial mining area. There is a fuller understanding of the occurrence of radioactive elements in water bodies.

\section{References}

1. Wang Yi, Liang Hongkun, Shao Zhitao, et al. Decoding the geological environmental problems of mines with pictures and texts. China Mining Industry, 2020, 29(S2): 98-101.

2. Chen Lide, Zhao Jiancang. Discussion on the economics of the development and utilization of an iron mine in Gansu. Jiugang Science and Technology, 2019(02):40-43.

3. [Luo Shixing, Zhou Wei. Analysis of the temporal and spatial differentiation of my country's mining land and its influencing factors. Science and Technology Management of Land and Resources, 2020, 37(05): 59-69.

4. Wu Haiyan. Geological environmental problems of open-pit mining and restoration measures. Housing and Real Estate, 2020(30): 251-252.

5. Zhang Yanjiao, Li Yuanyuan. Discussion on the current situation and development of radiation environment monitoring in my country. Environmental Science Guide, 2018, 37(S1): 172174.

6. Huang Libin, Zhong Zhijing, Zhou Bank, et al. Research on radiation monitoring process management system. Information and Computer (Theoretical Edition), 2017(23): 136-137.

7. Zhu Li, Wang Jin, Liu Juan, et al. Preliminary study on simulated leaching experiment of uranium, thorium and some metals in uranium tailings. Environmental Chemistry, 2013, 32(04): 678-685.

8. Zhang Bin. The impact of uranium, thorium and heavy metals in the uranium waste rock pile on the surrounding soil environmental quality. World Nonferrous Metals, 2017(21):283-286. 